\title{
Captive-Reared Dusky Grouper (Mycteroperca marginata) As an Alternative to Repopulation of Degraded Reef Habitats
}

\author{
Ralf Riede $^{l^{*}}$, Cláudia Keber, Gabriel Correal, Mauricio Mata Jr, Fernando Castro-Cardoso
}

Project Grouper, ATEVI, Ilhabela - SP, Brazil

"Corresponding author: Ralf Riedel, Project Grouper, ATEVI; Ilhabela-SP, Brazil. Tel: +4961511621623/24; Email: ralf.riedel@, usm.edu

Citation: Riedel R, Keber C, Correal G, Mata Jr M, Cardoso FC (2017) Captive-Reared Dusky Grouper (Mycteroperca marginata) As an Alternative to Repopulation of Degraded Reef Habitats. J Fish Aquac Dev: JFAD-114. DOI:10.29011/JFAD-114/100014

Received Date: 03 July, 2017; Accepted Date: 23 July, 2017; Published Date: 31 July, 2017

\begin{abstract}
Captive fish have been extensively used for stock enhancement and conservation of coastal and marine habitats. Evaluation of the effectiveness of this practice, however, has not been as extensively demonstrated. Here we assessed acclimation of captivereared dusky grouper to reef habitats as an indication of introduction success. Fish were reared in laboratory from eggs obtained from wild local stocks to early juvenile stage (approximately $5 \mathrm{~cm}$ total length). Early juvenile fish were transported to fish pens for grow out to approximately $20 \mathrm{~cm}$ total length. Fish were individually tagged with acoustic transmitters and released after the grow out phase. Tagged fish were released at three reef habitat stations. Two stations received five fish each and one received 15 fish. Tagged fish were monitored for 7 months. We observed high mortality at the station receiving 15 fish and low mortality at the other stations. Behavior of fish demonstrated a pattern of refuge use according to time-of-day following approximately 5 days of release. Tagged fish behavior indicated adaptation to new habitat, demonstrating that captive groupers are a viable option in population recovery of degraded reef habitats.
\end{abstract}

Keywords: Conservation; Dusky Grouper; Mari Culture; Recovery; Reef Restoration; Telemetry

\section{Abbreviations:}

IUCN : $\quad$ International Union for Conservation of Nature

GnRHa : $\quad$ Gonadotropin-Releasing Hormone Agonist

IBAMA : $\quad$ Instituto Brasileiro do Meio Ambiente e dos Recursos Naturais Renováveis (Brazilian Environment and Renewable Natural Resources Institute)

Vemco : $\quad$ Acoustic Telemetry Company

V9 : : Vemco $9 \mathrm{~mm}$ transmitter

VR2W : $\quad$ Vemco $69 \mathrm{kHz}$ receiver

\section{Introduction}

With the increasingly threat from anthropogenic disturbances to marine environments, biodiversity is eroding at alarming rates, even faster than new species are being discovered $[1,2]$. Reduction of species may negatively affect human communities economically and socially by causing irreversible knock-on effects toward degradation of habitats harboring economically and ecologically important species. Unbalances caused by erosion of biodiversity may come about from breaking interactions among species. Such effects have mostly unknown consequences, but are generally agreed to be negative [3-7]. Efforts to protect one species, although less preferred over protecting assemblages, may be justified more strongly when this species is key in regulating an ecosystem, such as with top predators. Dusky groupers (Micteroperca marginata) may be fall under such group, as its presence contributes to the maintenance and viability of ecosystems $[8,9]$.

Dusky groupers in Brazil are widely distributed throughout its southeastern and southern coast $[10,11]$. This species is sedentary, have a high site fidelity, and a low growth rate [12-15]. Dusky groupers are listed as threatened by the IUCN, especially due to overfishing and habitat degradation [16]. In Brazil, even though listed as over-exploited by regulating authorities, there is little more than length limits attempting to manage its fishery $[17,18]$. Lack of effective regulation, associated with its slow growth, late maturation, and behavioral characteristics, is contributing to the disappearance of this species along the coast of Brazil. Measures 


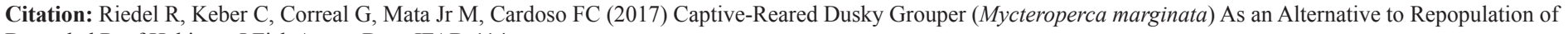
Degraded Reef Habitats. J Fish Aquac Dev: JFAD-114.

toward its protection and recovery are of immediate need.

Using captive-reared fish for enhancing stocks and repopulating degraded habitats has met with varying degrees of success over the years. Much skepticism existed in the past as to its efficiency in stock enhancement [19-22], but recent advances in mariculture and monitoring techniques have revived its adoption in recovery programs $[23,24]$. Such advances have contributed to recovery of invertebrates [25-28] and fish [29,30], especially sedentary fish with high habitat fidelity, as for dusky groupers.

The objective of this study was to investigate the viability of using captive-reared dusky groupers in population recovery of reef habitats. Mariculture of dusky groupers may still be cost prohibitive for commerical applications, but can be a viable alternative for conservation and management of this species. In a world where overfishing has gone unabated, tools to mitigate its effect need to be as diverse as the environments we are seeking to preserve. The opportunity to revert overfishing trends cannot rest solely on regulations, especially for slow growing species with a late maturation, as for dusky groupers.

\section{Materials and Methods}

Released fish from this study were produced in captivity from eggs to juveniles. Eggs were produced from wild dusky groupers induced to maturity with cholesterol and GnRHa [31] at $30 \mathrm{mg} /$ $\mathrm{kg}$. After fertilization, eggs were put in incubators at a $1 \mathrm{~g} / 1$ density until hatching. Larvae were fed rotifers for approximately 15 days post-hatching, followed by artemia for another 45 days. After the 60 days, 60 juvenile fish were selected and placed in net pens for growout. Growout fish were fed a fish diet daily to satiation. The growout phase lasted for 10 months, when juveniles reached 20 $\mathrm{cm}$ total length on average.

Twenty-five fish survived through the growout phase and used for the release phase. All twenty-five fish were implanted with an acoustic tag of $9 \mathrm{~mm}$ diameter (Vemco V9). Implants were conducted by an approximately $1 \mathrm{~cm}$ long abdominal incision. Fish were observed for mortality for two days after implants. After observation, fish were transported in oxygenated tanks to the release site (Figure 1). The release site was characterized by a rocky substrate of depths less than $10 \mathrm{~m}$. The release site was chosen based on prefered habitat for dusky groupers at the juvenile phase $[9,12]$. All released fish were tracked by acoustic receivers (Vemco VR2W) for 7 month post-release.

Stations 1, 2 and 3 were defined for receiver installation. Station 1 was at the southern most, Station 2 in the middle, and Station 3 at the northern most location within the study site (Figure 1). One acoustic receiver was placed at each station, separated from each other by $300 \mathrm{~m}$, the reach of receiver detection, at depths varying between 6 and $9 \mathrm{~m}$. Five tagged groupers were released at Station 1, 15 at Station 2, and five at Station 3. Fish acoustic sig- nals were downloaded from receivers at the end of the experiment and stored in a database for analyses. Telemetry analyses consisted of signal counts per day to detect signal appearance/disappearance patterns and frequency of signal disappearance for tagged fish. Signal disappearance from the detection dataset was interpreted as mortality.

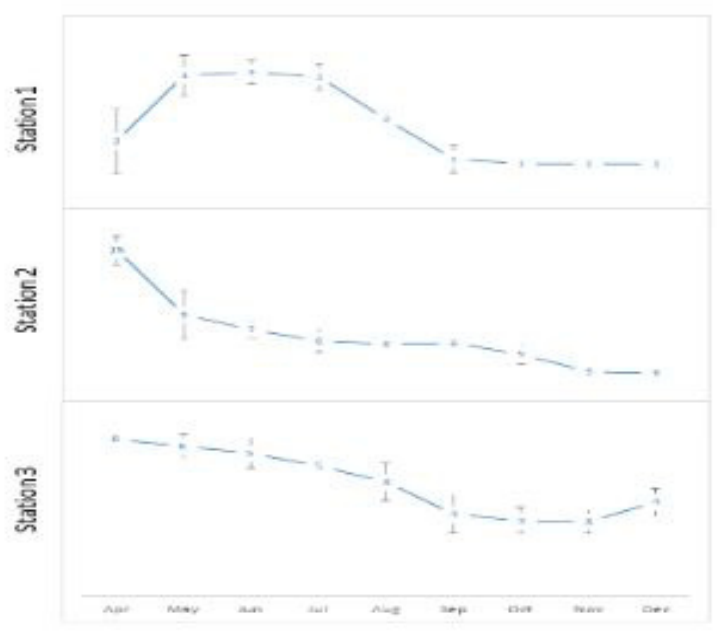

Figure 1: Study area and stations (in circles) used in telemetry studies on the coast of Rio de Janeiro State, Brazil.

As an alternative release experiment, larval fish were released to observe their behavior and estimate viability for stock recovery programs. Larval dusky grouper were placed in oxygenated plastic bags and taken to the release site. Experiment were conducted over two days. The release site comprised of reef habitats approximately $6 \mathrm{~m}$ deep. Larval release was conducted at 3 $\mathrm{m}$ depth to afford an opportunity for fish to move either to the surface or the substrate. Three bags with approximately 100 larvae each and 3 with approximately 500 larvae each were opened at the release site. This same operation was repeated the next day at a similar site in a different location. After release, larvae were followed by divers for one minute and observed as to their average movement direction.

\section{Results and Discussion}

Technological improvements in telemetry allow greater numbers of fish to be tracked at a reduced cost. Information as to home-range, habitat preference, inter- intra-specific interactions, migratory patterns, and distribution are but a few examples where telemetry excels at providing knowledge on fish and fisheries ecology. This knowledge, in turn, may prove essential for conservation of ecosystems and management of commercially important species [32-35].

Telemetry data suggested that groupers produced in captivity acclimated to reef habitats to varied degrees. There was higher mortality, as indicated by disappearance of acoustic signal, at Sta- 


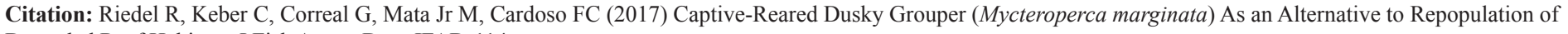
Degraded Reef Habitats. J Fish Aquac Dev: JFAD-114.

tion 2, where 15 individuals were released. Five individuals survived to the end of the 7-month experimental period at Station 2. At Station 1, only one individual remained through the experimental period (Figure 2).

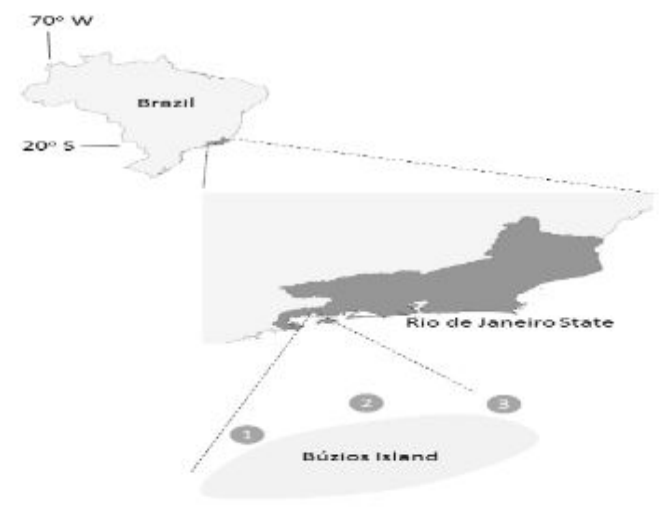

Figure 2: Monthly mean \pm standard deviation of numbers of juvenile dusky grouper following telemetry studies on the coast of Rio de Janeiro State, Brazil.

At Station 1, however, there were only 2 individuals detected from the start of the experiment. This may be due to either failure of transmitters in the other 3 individuals released, or because those same 3 individuals immediately left the receiver's area of detection. At Station 3, there was no loss of signal from any of the individuals released, indicating complete acclimation.

Stations 1-3, although of similar environments, were located at least $300 \mathrm{~m}$ apart from one another. Moreover, the orientation of the shoreline from the island where releases were performed were different among the stations. Station 3 faced north, while Station 1 and 2 faced east. The difference in orientation could partly explain the different degrees in acclimation, due possibly to slight microhabitat differences [9,36,37]. Most probably, the differences were due to the numbers released. Groupers are known territorial species [12], which could explain the higher mortalities at Station 2.

Data in this study also indicated the reappearance of acoustic signals after a period of disappearance of the signal. This may be due to the typical behavior of groupers when seeking shelter $[9,38]$. Groupers may spend the hours of daytime hiding in holes and crevices of their habitat. When in shelters, the acoustic signal may be weak or non-existent, due to interference of the rocky hard substrate. Active seeking of shelter is one more indication of the high degree of adaptability and acclimation of groupers raised in captivity to their natural environment. This calls for telemetry studies, such as this one, to extend in duration for at least a few days, to be able determination of degree of fish acclimation to the new habitat.

For habitats similar to the experimental study from this work, an optimal number to release groupers for population re- covery centers around 5 juvenile individuals per $600 \mathrm{~m}$ shoreline. Certainly, the release of 15 individuals was excessive and counterproductive. This result should be considered in programs aiming at recovery and enhancement of grouper stocks in habitats where overfishing or degradation has taken place. The result of this study does not only have managerial applications, but also economic implications. The cost of producing groupers in captivity is still prohibitive for commercial undertakings, but may be justified in marine conservation. If, however, an excessive number of juvenile groupers is released, conservation programs may be deemed ineffective, their success never being realized. Results from studies such as this may avoid premature conclusions being drawn against potentially effective conservation tools.

Data on release of captive-reared groupers in their larval stages showed the expected behavior for fish during this life-stage. All larvae were as active during release as they were when collected, indicating little or no stress during the trip from the aquaculture facility to the release site. Without exception, larvae were positively phototactic, without much dispersion during release, indicating a strong pattern to surface migration during this life-stage. Due to the high probability of predation, using larval groupers in repopulation programs may only be effective when large numbers of larvae are employed. Using larvae in fish release programs has a cost advantage over releasing juveniles. Employing larvae also allows for a much higher number of released individuals. The transition from larvae to juvenile in captivity is associated with a high mortality, sometimes close to 100 percent. This could be due to the techniques used in laboratory. If this is the case, releasing larvae has yet the additional advantage of keeping metamorphosisrelated mortality to a minimum. The downside of releasing larvae, however, is the as of yet rudimentary means to track released fish, which make estimating this alternative weak at best for stock recovery. It is, however, encouraging that all observed larvae did behave as expected, demonstrating immediate acclimation to the natural environment.

In conclusion, grouper aquaculture may still fall short of economic viability for commercial ventures. Groupers raised for market need to reach a size that may not come about before two or three years from larvae. Also, during metamorphosis from larvae to juvenile, high mortality, sometimes, total, may be observed $[39,40]$. Alternatively, grouper raised for stock replenishment may be viable, if the right life-stage and numbers are employed during release. This study demonstrated that groupers raised in captivity are highly adaptable and readily acclimate to reef and rocky environments. The foundation has been laid. The next step to build on that foundation is to undertake studies to determine the quantities of fish to be released and at what life-stage. The results of such studies will depend on the environment being studied and on the budget for conservation projects. According to the findings herein, however, the optimal numbers and most adequate life-stage seem 
Citation: Riedel R, Keber C, Correal G, Mata Jr M, Cardoso FC (2017) Captive-Reared Dusky Grouper (Mycteroperca marginata) As an Alternative to Repopulation of Degraded Reef Habitats. J Fish Aquac Dev: JFAD-114.

to approximate 5 juveniles $(20 \mathrm{~cm})$ groupers per $600 \mathrm{~m}$ shoreline of rocky reefs.

\section{References}

1. Pimm SL, Jenkins CN, Abell R, Brooks TM, Gittleman JL, et al. (2014) The biodiversity of species and their rates of extinction, distribution, and protection. Science 344: 1246752.

2. Ceballos G, Ehrlich PR, Barnosky AD, Garcia A, Pringle RM, et al. (2015) Accelerated modern human-induced species losses: entering the sixth mass extinction. Sci Adv 1: 1-5.

3. Ives A, Cardinale B (2004) Food-web interactions govern the resistance of communities after non-random extinctions. Nature 429: 174177.

4. Solan MB Cardinale, A Downing, K Engelhardt, J Ruesink, D Srivastava (2004) Science 306: 1177-1180.

5. Bascompte J (2009) Disentangling the web of life. Science 325: 416419.

6. Donnelly A, Caffarra A, O'Neill BF (2011) A review of climate-driven mismatches between interdependent phenophases in terrestrial and aquatic ecosystems. International Journal of Biometereology 55: 805817.

7. Hughes L (2012) Climate change impacts on species interactions: assessing the threat of cascading extinctions. in Saving a Million Species: Extinction Risk from Climate Change, L. Hannah (ed.). Island Press, New York: 337-359.

8. Goeden G (1982) Intensive fishing and a keystone predator species: ingredients for community instability. Biological Conservation 22: 273281.

9. La Mesa G, Louisy P, Vacchi M (2002) Assessment of microhabitat preferences in juvenile dusky grouper (Epinephelus marginatus) by visual sampling. Marine Biology 140: 175-185.

10. Menezes N (1980) Manual de peixes marinhos do sudeste do Brasil, III. Teleostei. Museu de Zoologia da Universidade de São Paulo, São Paulo: 90 .

11. Rico MR, Acha EM (2003) Southernmost occurrence of Epinephelus marginatus in the south-west Atlantic. Journal of Fish Biology 63: $1621-1624$

12. Harmelin JG, Harmelin-Viviene M (1999) A review on habitat, diet and growth of the dusky grouper Epinephelus marginatus (Lowe, 1834). Marine Life 9: 11-20.

13. Lembo G, Spedicato MT, Okland F, Carbonara P, Fleming IA, et al. (2002) S wireless communication system for determining site fidelity of juvnile dusky grouper Epinephelus marginatus (Lowe, 1834) using coded acoustic transmitters. Hydrobiologia 483: 249-257.

14. Andrade AB, Machado LF, Hostim-Silva M, Barreiros JP (2003) Reproductive biology of the dusky grouper Epinephelus marginatus (Lowe, 1834). Brazilian Archives of Biology and Technology 46: 373-381.

15. Renones O, Pineiro C, Mas X, Goni R (2007) Age and growth of the dusky grouper Epinephelus marginatus (Lowe 1834) in an exploited population of the western Mediterranean Sea. Journal of Fish Biology 71: 346-362.
16. Cornish A, Harmelin-Vivien M (Grouper \& Wrasse Specialist Group) (2004) Epinephelus marginatus. In: IUCN 2012. IUCN Red List of Threatened Species. Version 2012.2.

17. IBAMA (2003) Ministério do Meio Ambiente. Instituto Brasileiro do Meio Ambiente e dos Recursos Naturais Renováveis (IBAMA). Portaria $n^{\circ}$ 73/03-N. Ministério do Meio Ambiente, Brasília.

18. IBAMA (2004) Ministério do Meio Ambiente. Instituto Brasileiro do Meio Ambiente e dos Recursos Naturais Renováveis (IBAMA). Instrução Normativa $n^{\circ} 3$. Ministério do Meio Ambiente, Brasília.

19. Kitada S, Taga Y, Kishino H (1992) Effectiveness of stock enhancement program evaluated by a two-stage sampling survey of commercial fisheries. Canadian Journal of Fisheries and Aquatic Sciences 49: 1573-1582.

20. Smedstad O, Salvanes A, Fossa J, Nordeide J (1994) Enhancement of cod, Gadus morhua L., in Masfjorden: an overview. Aquaculture and Fisheries Management 25 (Supplement 1): 117-128.

21. Blankenship H, Leber K (1995) A responsible approach to marine stock enhancement. American Fisheries Society Symposium 15: 167-175.

22. Hilborn R (1998) The economic performance of marine stock enhancement programs. Bulletin of Marine Science 62: 661-674.

23. Bell J, Leber K, Blankenship H, Loneragan N, Masuda R (2008) A new era for restocking, stock enhancement and sea ranching of coastal fisheries resources. Reviews in Fisheries Science 16: 1-9.

24. Tringali MD, Leber KM, Halstead WG, McMichael R, O'Hop J, et al. (2008) Marine stock enhancement in Florida: a multi-disciplinary, stakeholder-supported, accountability-based approach. Reviews in Fisheries Science 16: 51-57.

25. Lovatelli A, Conand C, Purcell S, Uthicke S, Hamel J, et al. (2004) (Editors) Advances in sea cucumber Aquaculture and Management. Fisheries Technical Paper 463. FAO, Rome.

26. Uki N (2006) Stock enhancement of the Japanese scallop Patinopecten yessoensis in Hokkaido. Fisheries Research 80: 62-66.

27. Wang Q, Wu H, Fang J, Wang S (2006) Stock enhancement and sea ranching: practices at Zhangzidao Island in the northern Yellow Sea.

28. Wang Q, Zhuang Z, Deng J, Ye Y (2006) Stock enhancement and translocation of the shrimp Penaeus chinensis in China. Fisheries Research 80: 67-79.

29. Kitada S, Kishino H (2006) Lessons learned from Japanese marine finfish stock enhancement programmes. Fisheries Research 80: 101-112.

30. Hervas S, Lorenzen K, Shane M, Drawbridge M (2010) Quantitative assessment of a white seabass (Atractoscion nobilis) stock enhancement program in California: post-release dispersal, growth and survival. Fisheries Research 105: 237-243

31. Marino G, Panini E, Longobardi A, Mylonas CC (2003) Induction of ovulation in captive-reared dusky grouper, Epinephelus marginatus (Lowe, 1834), with a sustained-release $\mathrm{GnRHa}$ implant. Aquaculture 219: 841-858.

32. Holland K, Peterson J, Lowe C, Wetherbee B (1993) Movements, distribution and growth rates of the white goatfish Mulloides flavolineatus in a fisheries conservation zone. Bulletin of Marine Science 52: 982-992. 
Citation: Riedel R, Keber C, Correal G, Mata Jr M, Cardoso FC (2017) Captive-Reared Dusky Grouper (Mycteroperca marginata) As an Alternative to Repopulation of Degraded Reef Habitats. J Fish Aquac Dev: JFAD-114.

33. Holland K, Lowe C, Wetherbee B (1996) Movements and dispersal of blue trevally (Caranx melampygus) in a fisheries conservation zone. Fisheries Research 25: 279-292.

34. Zeller D (1997) Home range and activity patterns of coral trout Plectropomus leopardus (Serranidae). Marine Ecology Progress Series 154: 65-77.

35. Kramer D, Chapman M (1999) Implications of fish home range size and relocation for marine reserve function. Environmental Biology of Fishes 55: 65-79.

36. Kramer M, Bellwood O, Bellwood D (2016) Foraging and microhabitat use by crustacean-feeding wrasses on coral reefs. Mar Ecol Prog Ser 548: 277-282.
37. Medeiros P, Moreira A, Medeiros A (2016) Local variations in microhabitat use by Stegastes fuscus (Cuvier, 1830) (Teleostei: Pomacentridae) in a tropical reef of Brazil. Braz J of Biol Sci 3: 375-384.

38. Mercader M, Fontcuberta A, Mercière A, Saragoni G, Lenfant P, et al. (2016) Observation of juvenile dusky grouper (Epinephelus marginatus) in artificial habitats of North-Western Mediterranean harbors. Mar Biodiv.

39. Kerber C, Santos P, Silva P (2011) Criação da garoupa. Panorama da Aqüicultura 22: 27-33.

40. Kerber C, Silva H, Santos P, Sanches E (2012) Reproduction and larviculture of dusky grouper Epinephelus marginatus (Lowe 1834) in Brazil. Journal of Agricultural Science and Technology 2: 229-234. 